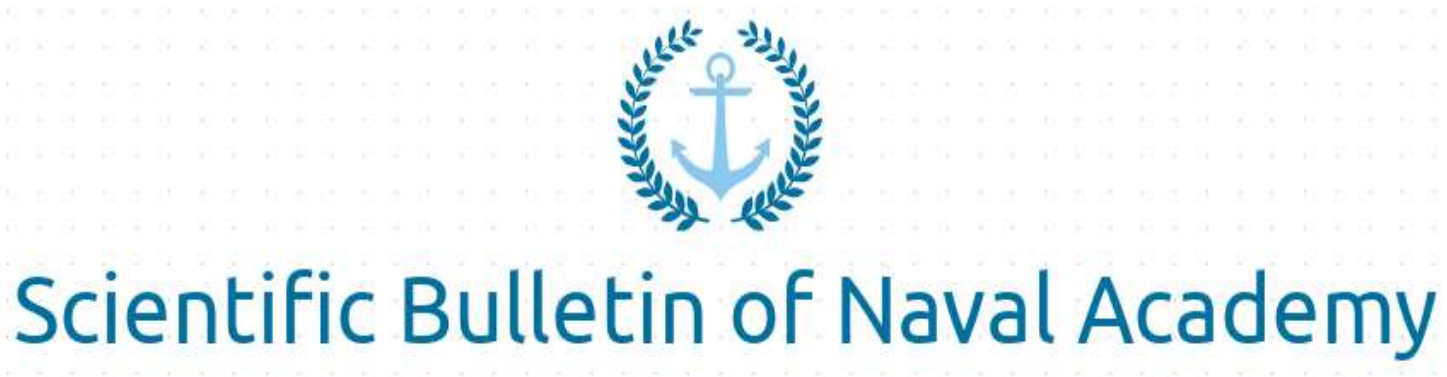

SBNA PAPER • OPEN ACCESS

\title{
Assessment of training in the naval pentathlon
}

To cite this article: Constantin Cristinel OLARU, Scientific Bulletin of Naval Academy, Vol. XXIII 2020, pg.311-319.

Available online at www.anmb.ro

ISSN: 2392-8956; ISSN-L: 1454-864X 


\title{
Assessment of training in the naval pentathlon
}

\author{
PhD student Constantin Cristinel OLARU
}

City of Constanta, Constanta county, Bobîlna street, no.25 a, postal code 900002

Email: olarucristinel@yahoo.com

National University of Physical Education and Sport Bucharest

\begin{abstract}
The performance performed by the athlete in the competition depends on its ability to solve the complex situation specific to that competition. The factors that create these locations may be of an internal nature, represented by the individual characteristics of the athlete (psychomotor and intellectual skills, attitudes, adaptability to changes in the situation), or of an external nature (social, environmental, specific factors) [14]. In order to achieve maximum performance, the athlete must respond optimally to the interaction of specific internal and external factors.

The evaluation is one of the integral parts of the instructional-educational process, and the results of the evaluation reflect the effectiveness of the efforts of the coach and the team involved in the training of athletes. At the same time, the evaluation process will ensure an objective knowledge of the training process ensuring its adjustment and optimization.
\end{abstract}

\section{Keywords: training, evaluation, naval pentathlon}

\section{Introduction}

Evaluation, as part of the instructional-educational process, can be defined as a "process", a "stated activity",a "psychopedagogicalact",, or in the case of our research a "managerialaction".

It is wrong to consider evaluation as a step that would follow learning in the training process. Evaluation is considered to be an ongoing process, being permanently interconnected with the teaching-learning process and having a strong formative role achieved through appropriate feedback.

In the management of sports competitions, specialists analyze the evaluation in the control-assessment-guidance triad, which is considered a managerial function [14] in which "control and evaluation must beaccompanied by a sustained activity of guidance"

Evaluation is a "complex process of comparing the results of the instructional-educational activity with the planned objectives (quality assessment), with the resources used (efficiency assessment) or with the previous results (progress assessment)" [9];

Evaluation is "the process that begins with planning and describing the objectives and content to be controlledlater" [13]

Optimizing the evaluation process requires the evaluator to take into account the following aspects:

- Why I evaluate (for knowledge of the performance and progress of those evaluated, optimization of evaluation techniques and tools, optimization of teaching strategies);

- What I assess (the extent to which the objectives of the training have been achieved, skills, attitudes, organization and conduct of the instructional process, progress made);

- Who uses the evaluation (evaluator, institution, evaluated);

- When I evaluate (at the beginning, during, at the end of the instructional-educational process);

- How I evaluate (techniques and procedures, tests used, samples, scales) [6]

- Who Do I Evaluate (Coach, Athletes)

Continuity of evaluation and connection with other elements of the training process involves:

- Continuity in the organization and training of skills

- Continuity and connection between skills training stages and motor capacity development 
- Continuity in the design of the final objectives

- Continuity in the application of training and evaluation strategies

The evaluation process assumes the existence of the following components: control (verification), quantitative analysis (measurement), qualitative analysis (assessment of results) and elaboration of the decision on the efficiency of the training process.

As a step-by-step training process, the evaluation of the effectiveness of training in naval pentathlon has the following forms:

- Initial diagnostic/selection assessment;

- Current evaluation, which will have a formative role;

- Final (summative) assessment.

The initial evaluation in training aims to obtain information on the actual psycho-motor level of athletes and the conditions necessary for training and maximizing their performance. Based on this information, the coach will choose the most effective preparation strategies for achieving the goals.

The initial assessment 'is indispensable in determining whether the subjects have the necessary training to create favourable premises for a newlearning' [4].

The role of the current evaluations will be that during the preparation process, through continuous feedback, the coach optimizes the training process in order to maximize performance. The formative evaluation supports the maintenance of an evaluative flow aimed at ensuring a punctual and continuous progress. At the same time, the formative evaluation identifies the difficulties faced by the subject (the athlete) in the training/training process and aims to achieve the proposed objectives $[2,11]$. This type of assessment is not intended to establish a hierarchy but compares the performance achieved with the pre-established intermediate objectives [10].

Judging by the functions of the evaluation [16], the initial evaluation performs the diagnostic and forecasting function on the work to be carried out, and the current evaluation serves to correct possible malfunctions in the subject's work by providing feedback and motivational support in the training process [5,12].

Summative evaluation is an assessment that provides a review of the training over a certain period, indicating by the results offered a progress of the subjects. In doing so, the evaluator shall make a diagnosis of the achievement of the general objectives set for the end of the training period in relation to the final expectations or objectives initially set.

This type of assessment certifies that the subject has achieved a certain level of training and at the same time helps to establish a hierarchy between subjects.

Summative evaluation is also intended to confirm or disprove the effectiveness of the teacher/coach's performance, the strategies used and the value of the training programmed.

The effectiveness of the evaluation is apparent from the following aspects:

- Obtaining information on the achievement of the objectives proposed in the training process;

- Making a diagnosis of the progress of the subjects evaluated;

- Linking the subjects' actions to their possibilities in the training process;

- Determination of the causes that have generated constant deviations and the orientation of the subjects towards an optimal means of affirmation

- Providing useful information to improving the instructional process, fixing new aspirations

- Evaluation of the instructional process to help the coach (teaching staff) in self-assessment [3] The effectiveness of the training is determined by the original combination of several factors: [7]

- Programming and design of preparation 
- Measurement and evaluation techniques applied

- Training content

- Technical means of carrying out training

- Psycho structure (sportsman)

- Content of the sports branch (programmed)

- Social framework

- Coach and team of specialists

Evaluation methods are the way in which the coach/teacher gives the subjects the opportunity to demonstrate the level of training obtained and the ability to use this training [8].

\section{Summary}

2.1. The aim of the research is to optimize management in the training of the naval pentathlon, by applying the evaluation methods properly and making objective use of the results obtained.

\subsection{Research hypothesis}

The research started from the premise that carrying out an objective evaluation of athletes, organized and applied effectively [15], throughout the period of a training macrocycle, will ensure the achievement of the training objectives and maximizing the performance achieved in the planned competitions.

Research is defined by the optimisation of the evaluation process applied continuously and in permance in the "control-assessment-guidance triad" [14]

2.4. Research objectives

- Highlighting the effectiveness of the competitive activity of athletes in the naval pentathlon group by reporting the results of the competitions to the previously forecast and established performance targets [17];

- Verification and assessment of the level of motor capacity development;

- Testing of functional capacities (aerobic, anaerobic) with a decisive role in the efficiency of competitive activity;

- Knowledge of the body's reaction to training efforts and the peculiarities of fatigue and recovery processes.

2.5. Methods used in research

- Study of literature, including by accessing electronic databases

- Application of tests and measurements adapted to naval pentathlon samples (anthropometric and functional measurements, general and specific motor capacity testing)

- Pedagogical observation applied to track the obvious changes in the psychomotor behavior of athletes. Through the observation we carried out the data collection by direct finding from the subjects of the research activity. The observation applied in the research was of a systematic nature, directed and carried out according to a rigorous plan. [1]

- Statistical-mathematical method

- Experimental method

2.6. Organization and conduct of research

The evaluation of the effectiveness of the training in our paper takes into account the period of a seven-month training macro cycle, which is a preliminary preparation period for a larger experimental research. 
The research took place within the Naval Academy "Mircea the Elder"with a number of 30 military students, selected by specific tests, used in the evaluations in the curriculum and an opinion questionnaire through which we followed the motivational level for the practice of performance sport. The results of the questionnaire were the criterion for dividing the 30 students into two samples: a blank sample which underwent sports training according to the curriculum and an experimental sample which followed a sports training program organized in a macro cycle, with means and methods of training specific to the naval pentathlon.

\subsection{Results}

The evaluation of the two samples was planned in the training plan according to the stages of evolution of the athletes and the training objectives.

Thus, the initial evaluation was planned at the end of the adjustment phase of the training plan, 30 days after the start of training. Through this evaluation we carried out a diagnosis of the general, specific motor level and morphological and physiological characteristics of athletes (Table 1)

Table 1 Main statistical indicators of research - initial assessment

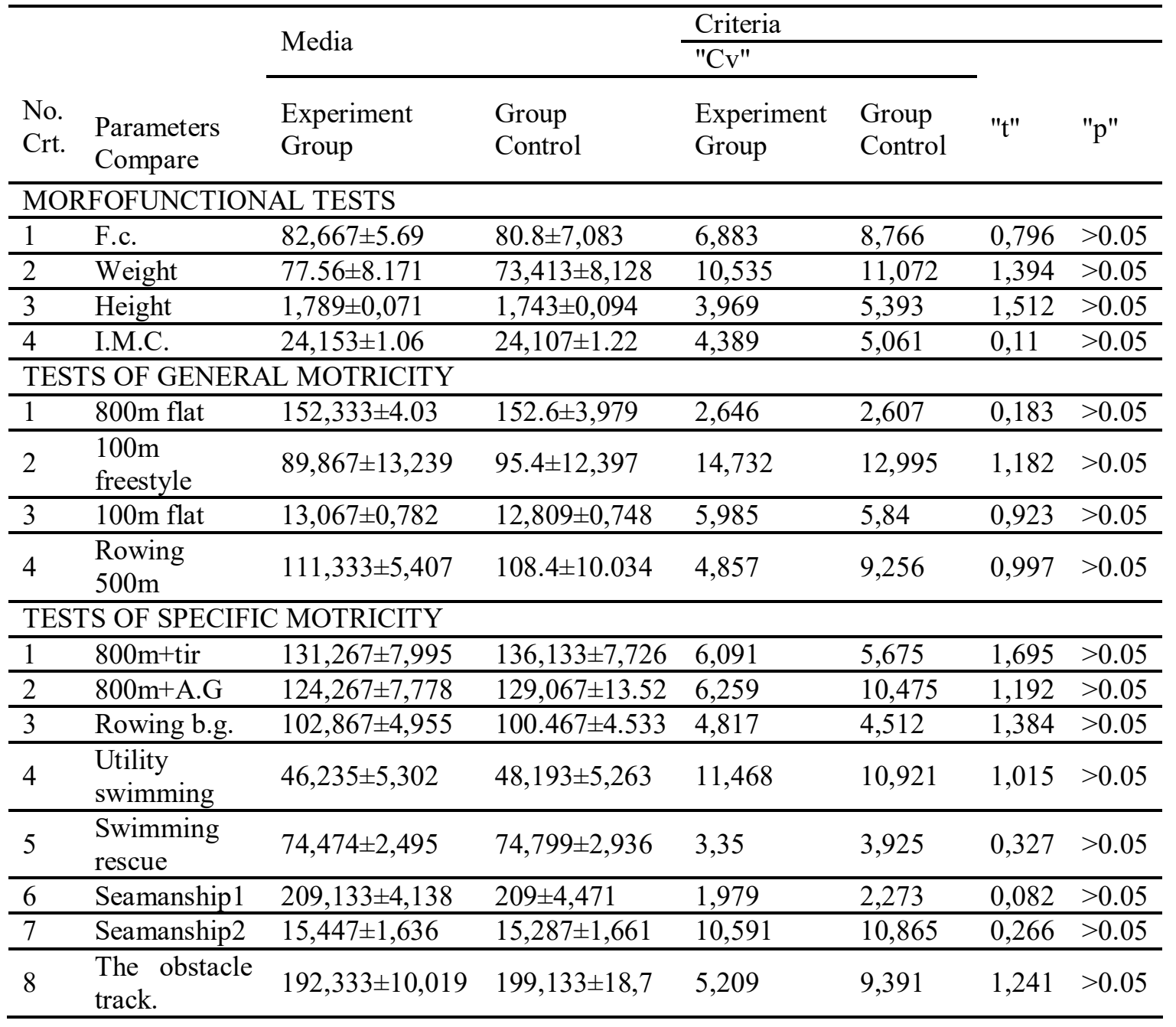

In the general motor test, the values recorded by the subjects in the $800 \mathrm{~m}$ flat, $100 \mathrm{~m}$ free, running $100 \mathrm{~m}$ flat and rowing $500 \mathrm{~m}$ at the rowing ferry were statistically analyzed. 
The average record performance for the component subjects of the two research groups is slightly superior in favor of the experiment group, but the difference is statistically insignificant for all four tests. According to the variability index, the value population is homogeneous, with the exception of the $100 \mathrm{~m}$ free swimming test, where the recorded values indicate an average homogeneity for both groups.

Specific motor testing in the initial testing of the subjects materialized by applying the relevant for naval pentathlon samples. The results obtained and the main statistical parameters presented in the table indicate better performance for the experiment group in most cases, but the differences between the experiment and control groups are not statistically significant.

The formative evaluation was carried out continuously throughout the preparation period, but for an objective assessment we planned these evaluations at the end of the accumulation periods. Depending on the evolution of the psycho-motor level of the athletes we applied methods of individualization of preparation to maximize the performance of training and competition.

The summative, final evaluation was used to assess athletes' performance before the competition period. It was intended to establish a hierarchy within the experimental team to facilitate the selection of the representative group, consisting of 6 athletes. The results of this final evaluation are presented in Table 2 .

Table 2 Main statistical indicators of research - final evaluation

\begin{tabular}{|c|c|c|c|c|c|c|c|}
\hline \multirow[b]{3}{*}{$\begin{array}{l}\text { No } \\
\text { Crt }\end{array}$} & \multirow[b]{3}{*}{$\begin{array}{l}\text { Parameters } \\
\text { Compare }\end{array}$} & \multirow{2}{*}{\multicolumn{2}{|c|}{ Media }} & \multicolumn{4}{|l|}{ Criteria } \\
\hline & & & & "Cv" & & & \\
\hline & & Experiment Group & $\begin{array}{l}\text { Group } \\
\text { Control }\end{array}$ & \multirow[t]{2}{*}{$\begin{array}{l}\text { Experiment } \\
\text { Group }\end{array}$} & $\begin{array}{l}\text { Group } \\
\text { Control }\end{array}$ & "t" & "p" \\
\hline \multicolumn{7}{|c|}{ MORFOFUNCTIONAL TESTS } & \\
\hline 1 & F.C. & $81 \pm 4,598$ & $79,867 \pm 6,058$ & 5,677 & 7,585 & 0,577 & $p>0.05$ \\
\hline 2 & Weight & $77,567 \pm 6,605$ & $73,413 \pm 8,128$ & 8,515 & 11,072 & 1,536 & $\mathrm{p}>0.05$ \\
\hline 3 & Height & $1,801 \pm 0,057$ & $1.75 \pm 0,088$ & 3,165 & 5,024 & 1,884 & $\mathrm{p}<0.05$ \\
\hline 4 & I.M.C. & $23,853 \pm 0,695$ & $23,787 \pm 0,751$ & 2,914 & 3,157 & 0,724 & $\mathrm{p}>0.05$ \\
\hline \multicolumn{8}{|c|}{ TESTS OF GENERAL MOTRICITY } \\
\hline$\overline{1}$ & $800 \mathrm{~m}$ flat & $147,267 \pm 4,267$ & $150,667 \pm 3,436$ & 2,897 & 2,281 & 2,404 & $<0.025$ \\
\hline 2 & $\begin{array}{l}100 \mathrm{~m} \\
\text { freestyle }\end{array}$ & $86.067 \pm 11.455$ & $92,933 \pm 11,566$ & 13,626 & 12,446 & 2,109 & $<0.025$ \\
\hline 3 & $100 \mathrm{~m}$ flat & $12,493 \pm 0,608$ & $12,867 \pm 0,425$ & 4,867 & 3,303 & 1,953 & $<0.05$ \\
\hline 4 & Rowing $500 \mathrm{~m}$ & $98,467 \pm 4,688$ & $107,867 \pm 9.97$ & 4,761 & 9,243 & 3,304 & $<0.005$ \\
\hline \multicolumn{8}{|c|}{ TESTS OF SPECIFIC MOTRICITY } \\
\hline 1 & $800 \mathrm{~m}+$ tir & $125,93 \pm 4,096$ & $132.53 \pm 7,891$ & 3,253 & 5,954 & 2,875 & $<0.005$ \\
\hline 2 & $800 m+$ A.G & $116.2 \pm 4,362$ & $124,467 \pm 11.3$ & 3,754 & 9,079 & 2,643 & $<0.01$ \\
\hline 3 & Rowing b.g. & $96,067 \pm 4,166$ & $99,267 \pm 3,955$ & 4,337 & 3,984 & 2,158 & $<0.025$ \\
\hline 4 & $\begin{array}{l}\text { Utility } \\
\text { swimming }\end{array}$ & $42,554 \pm 4,013$ & $46,778 \pm 3,956$ & 9,43 & 8,457 & 2,903 & $<0.005$ \\
\hline 5 & $\begin{array}{l}\text { Swimming } \\
\text { rescue }\end{array}$ & $69,164 \pm 3,275$ & $73,746 \pm 3,074$ & 4,108 & 4,168 & 2,985 & $<0.005$ \\
\hline 6 & Seamanship 1 & $196,533 \pm 4,809$ & $204,667 \pm 5,678$ & 2,447 & 2,774 & 4,234 & $<0.0005$ \\
\hline 7 & Seamanship 2 & $15,973 \pm 1,059$ & $15,133 \pm 0,769$ & 6,63 & 5,082 & 2,486 & $<0.01$ \\
\hline
\end{tabular}




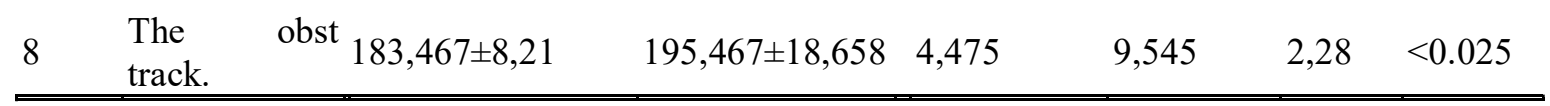

According to the results presented in the table, there are significant differences in the average performance of the two groups in favor of the experiment group for most tests.

By implementing the preliminary program in the preparation of the naval pentathlon lot, the performance of the experimental group compared to the control group has been improved.

Statistical interpretation for all tests applied in specific motor testing showed significant differences in favor of the experimental group.

The analysis of the dynamics of the results was aimed at highlighting from a statistical point of view the progress achieved by the experiment group following the application of the training program designed in the research work. The statistical indicators found in the table are the value mean of the two tests and the specific difference (M1 \pm DS1, M2 \pm DS2), the coefficient of variability (CV), the index of the independent test " $\mathrm{t}$ ", the significance threshold corresponding to its value (p) and the magnitude of growth (M.Cr.), expressed as a percentage.

Table 3 shows the averages of all parameters applied for morph functional testing, general motor testing and specific motor testing, compared between the initial evaluation, carried out at the beginning of the preparation of the test batch, and the final evaluation carried out before the competition period. Statistical results show a significant increase for all parameters compared in initial and intermediate testing.

Table 3 Main statistical indicators of research - dynamics of results - experiment group

\begin{tabular}{|c|c|c|c|c|c|c|c|c|}
\hline \multirow{3}{*}{$\begin{array}{l}\text { No } \\
\text { Crt }\end{array}$} & \multirow{3}{*}{$\begin{array}{l}\text { Parameters } \\
\text { Compare }\end{array}$} & \multicolumn{2}{|l|}{ Media } & \multicolumn{5}{|l|}{ Criteria } \\
\hline & & $\mathrm{M} 1 \pm \mathrm{DS} 1$ & $\mathrm{M} 2 \pm \mathrm{DS} 2$ & Cv1 & Cv2 & \multirow{2}{*}{-"t" } & \multirow{2}{*}{ "p" } & \multirow[b]{2}{*}{ M.Cr. } \\
\hline & & T.I. & T.f. & T.I. & T.f. & & & \\
\hline \multicolumn{9}{|c|}{ MORFOFUNCTIONAL TESTS } \\
\hline 1 & F.c. & $82,667 \pm 5.69$ & $81 \pm 4,598$ & 6,883 & 5,677 & 3,19 & $<0.005$ & $-2,017$ \\
\hline 2 & Weight & $77.56 \pm 8.171$ & $77,567 \pm 6,605$ & 10,535 & 8,515 & 0,012 & $>0.05$ & 0,009 \\
\hline 3 & Height & $1,789 \pm 0,071$ & $1,801 \pm 0,057$ & 3,969 & 3,165 & 2,965 & $<0.01$ & 0,671 \\
\hline 4 & I.M.C. & $24,153 \pm 1.06$ & $23,853 \pm 0,695$ & 4,389 & 2,914 & 2,097 & $<0.05$ & $-1,242$ \\
\hline \multicolumn{9}{|c|}{ TESTS OF GENERAL MOTRICITY } \\
\hline 1 & $800 \mathrm{~m}$ flat & $152,333 \pm 4.03$ & $147,267 \pm 4,267$ & 2,646 & 2,897 & 4,962 & $<0.0005$ & $-3,326$ \\
\hline 2 & $\begin{array}{l}100 \mathrm{~m} \\
\text { freestyle }\end{array}$ & $89,867 \pm 13,239$ & $84,067 \pm 11,455$ & 14,732 & 13,626 & 7,305 & $<0.0005$ & $-6,654$ \\
\hline 3 & $100 \mathrm{~m}$ flat & $13,067 \pm 0,782$ & $12,493 \pm 0,608$ & 5,985 & 4,867 & 6,246 & $<0.0005$ & $-4,393$ \\
\hline 4 & Rowing 500 & $111,333 \pm 5,407$ & $98.8 \pm 4.443$ & 4,857 & 4,443 & 6,463 & $<0.0005$ & $-11,257$ \\
\hline
\end{tabular}


TESTS OF SPECIFIC MOTRICITY

\begin{tabular}{|c|c|c|c|c|c|c|c|c|}
\hline 1 & $800 \mathrm{~m}+$ tir & $131,267 \pm 7,995$ & $125,933 \pm 4,096$ & 6,091 & 3,253 & 3,494 & $<0.005$ & $-4,063$ \\
\hline 2 & $800 \mathrm{~m}+\mathrm{A} \cdot \mathrm{G}$ & $124,267 \pm 7,778$ & $116.2 \pm 4,362$ & 6,259 & 3,754 & 4,753 & $<0.0005$ & $-6,492$ \\
\hline 3 & Rowing b.g. & $102,867 \pm 4,955$ & $96,067 \pm 4,166$ & 4,817 & 4,337 & 7,505 & $<0.0005$ & $-6,61$ \\
\hline 4 & $\begin{array}{l}\text { Utility } \\
\text { swimming }\end{array}$ & $46,235 \pm 5,302$ & $42,554 \pm 4,013$ & 11,468 & 9,43 & 5,938 & $<0.0005$ & $-7,962$ \\
\hline 5 & $\begin{array}{l}\text { Swimming } \\
\text { rescue }\end{array}$ & $74,474 \pm 2,495$ & $70,564 \pm 2,899$ & 3,35 & 4,108 & 6,481 & $<0.0005$ & $-5,25$ \\
\hline 6 & Seamanship 1 & $209,133 \pm 4,138$ & $196,533 \pm 4,809$ & 1,979 & 2,447 & 11,289 & $<0.0005$ & $-6,025$ \\
\hline 7 & Seamanship 2 & $15,447 \pm 1,636$ & $16,173 \pm 0,873$ & 10,591 & 5,398 & 1,86 & $<0.05$ & 4,7 \\
\hline 8 & $\begin{array}{ll}\text { The obst } \\
\text { track. }\end{array}$ & $192.33 \pm 10.019$ & $183.47 \pm 8.21$ & 5,209 & 4,475 & 9,805 & $<0.0005$ & $-4,61$ \\
\hline
\end{tabular}

The dynamics of the results are also relevant by the graphical comparative analysis between the initial -T.I. evaluation and the final -T.F. evaluation (Fig. 1, 2, 3 ).

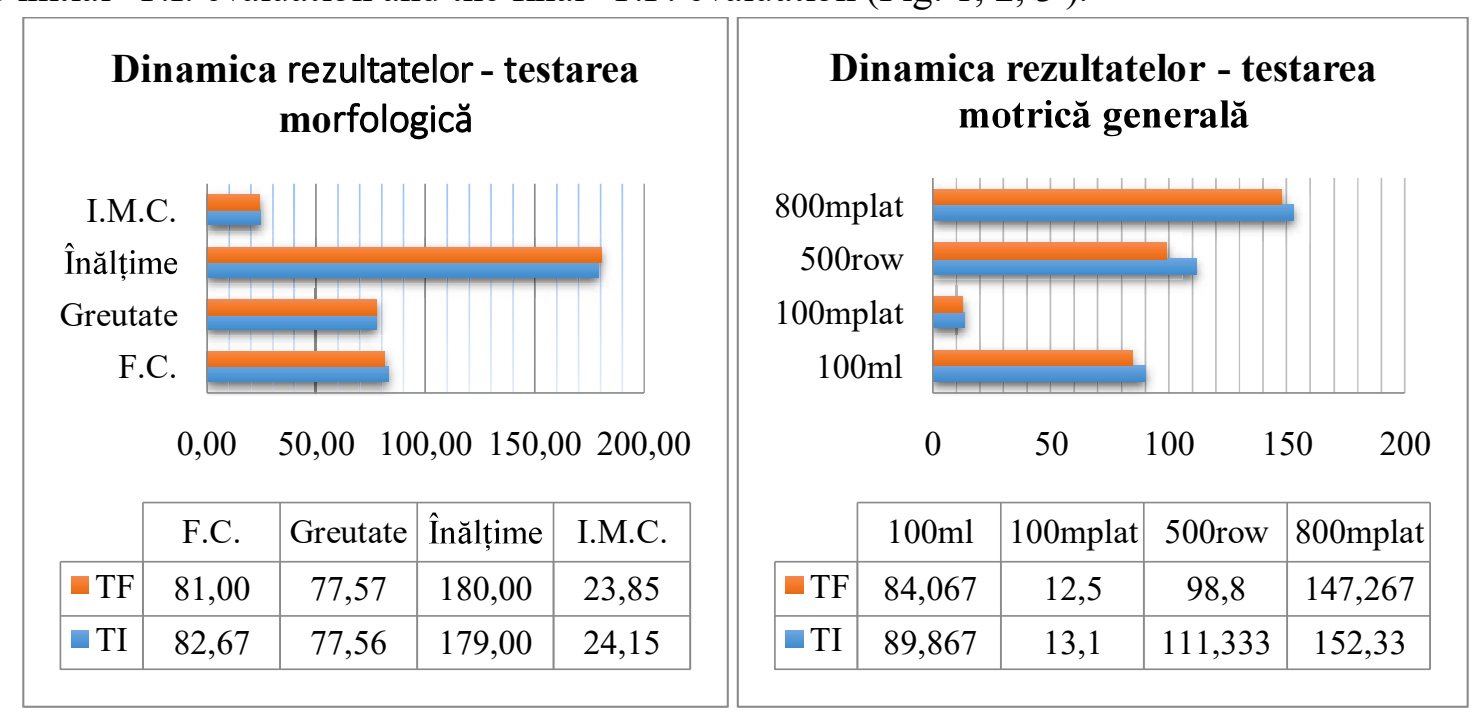

Fig. 1 Dynamics of morphological test results experiment - experiment group - TI/TF
Fig.2 Dynamics of motor general test results group- T.I./T.F 


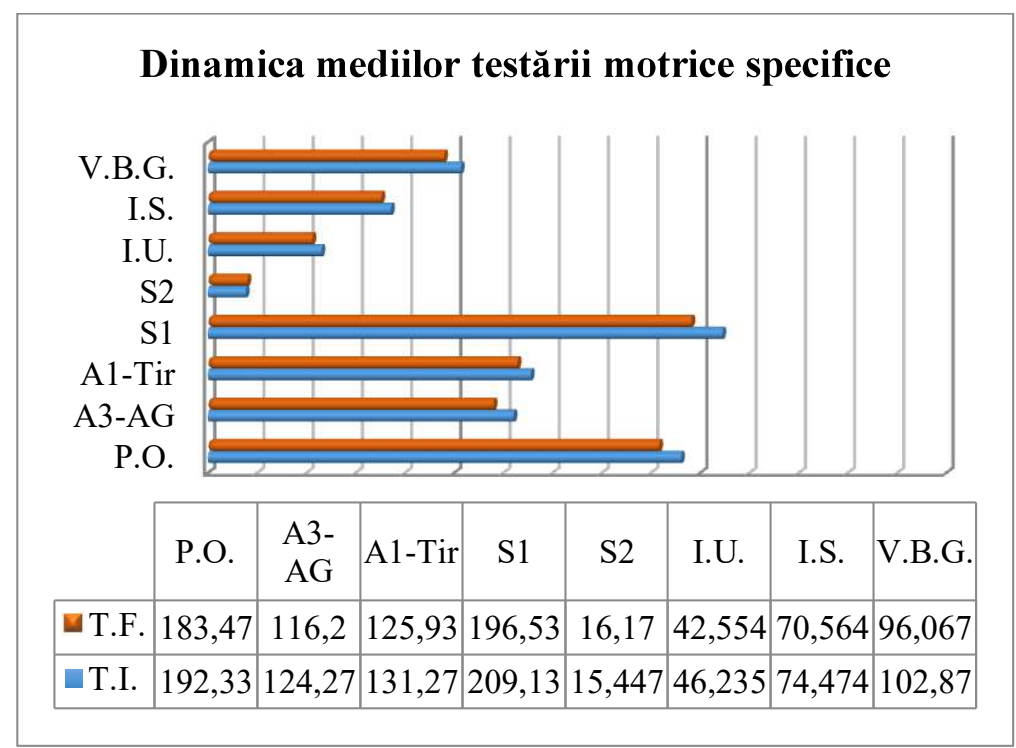

Fig.3 Dynamics of results in specific motor testing Experiment group - TI/TF

\section{Conclusions}

Comparative analysis of the results, based on mathematical-statistical and graphical methods, reveals significant increases in performance at the final testing stage in favor of the experiment group.

The dynamics of the results demonstrate a significant evolution of the results of the experiment group, carried out during the training program carried out according to the designed model, which confirms the effectiveness of the application of the training program.

Statistical calculation of the correlations between the performance of subjects recorded in morph functional, general and specific motor tests demonstrated a significant positive link in five of the correlations analyzed.

The designed training plan contains training lessons optimized for the usual conditions of the naval academy's learning process and with the resources in this situation.

The performance differences between initial and final testing, confirmed as significant by the application of statistical methods, demonstrate the effectiveness of the training plan designed on managerial principles.

The comparative analysis of the statistical results between the experiment and control group highlights significant increases in favor of the experiment group, which certifies that the selection methods applied are appropriate and contribute to the optimal improvement of the sporting performance of the representative batch of the naval academy.

\section{References}

[1] Anitei, M., 2000, Introduction to Experimental Psychology, Publishing House and Press Publishing House "Romanian Life", Bucharest, p. 35

[2] Balmer DF, Rama JA, Martimianakis MA, Stenfors-Hayes T. Use of data from qualitative research program evaluations. J Grade Med Educ. 2015; 8 (5): 773 - 774 . two: https://doi.org/10.4300/JGME-D-16-00540.1 [Google Scholar]

[3] Campbell, D., Lee, C., (1988). Self-Appraisal in Performance evaluation: Development Versus Evaluation, https://doi.org/10.5465/amr.1988.4306896

[4] Cerghit, I., (2008). Alternative and complementary training systems, Iaşi, Polirom Publishing House

[5] Clancy RB and all, 2017. Motivation Measures in Sport: A Critical Review and Bibliometric Analysis. Front. Psychol. 8:348. two: 10.3389/fpsyg.2017.00348 
[6] Colibaba, D., (2007), Praxiologie și proiectare curiculară în Educație fizică și sport, editura Universitaria, Craiova

[7] Dragnea, C.A., Mate-Teodorescu, S., (2002). Teoria sportului, București, editura Fest, p. 466

[8] Hoole, ER., Martineau, JW (2014). Evaluation methods. , Oxford Psychology Library. Oxford Handof Management and Organisations (p. 167-196). Oxford University Press.

[9] Jinga, I., et al, (1996), Evaluarea performanțelor școlare, editura Afeliu

[10] Mayer, G., (2000). De ce și cum evaluăm, Editura Polirom, Iași

[11] Richard, J.-F., Godbout, P., (2000). Formative evaluation as an integral part of the teaching-learning process, Physical Educatin and Health Journal 66 (3): cu 4 - de 10, Google Scholar

[12] Roberts, G.C., Treasure, D.C., (2001). Advances in Motivatin in Sport and Exercises, 3E. Champain, IL: Human Kinetics, Google Scholar.

[13] H., Schaub, K., Zenke, 2001. "Dicționar de pedagogie", editura Polirom

[14] Teodorescu, S., Ganera, C., 2013 p 182

[15] Wiggins, G. ( 1998) Educative Assessment: Designing Assessments to Inform and Improve Student Performance. San Francisco, CA: Jossey-Bass Inc. Google Scholar

[16] Wiliam, D. and Black, P. ( 1996) 'Meanings and Consequences: A Basis for Distinguishing Formative and Summative Functions of Assessment?', British Educational Research Journal 22(5): 537-48. Google $\underline{\text { Scholar }} \mid \underline{\text { Crossref }}$

[17] D'Isanto, T., et all, (2019) Assessment of Sport Performance: Theoretical Aspects and Practical Indications, DOI 10.26773/smj.190214 